\title{
BMJ
}

\section{Explaining variation in referral from primary to secondary care: cohort study}

\author{
Dulcie McBride, consultant in public health, ${ }^{1}$ Sarah Hardoon, statistician, ${ }^{2}$ Kate Walters, senior lecturer in \\ primary care, ${ }^{2}$ Stuart Gilmour, analyst, ${ }^{3}$ Rosalind Raine, professor of healthcare evaluation ${ }^{1}$
}

${ }^{1}$ Department of Epidemiology and Public Health, University College London, London WC1E 6BT, UK

${ }^{2}$ Department of Primary Care and Population Health, Royal Free and University Medical School, University College London, UK

${ }^{3}$ King's Fund, London, UK

Correspondence to: D McBride dulciemcbride@googlemail.com

Cite this as: $B M J$ 2010;341:c6267 doi:10.1136/bmj.c6267

\section{ABSTRACT}

Objectives To determine the extent to which referral for defined symptoms from primary care varies by age, sex, and social deprivation and whether any sociodemographic variations in referral differ according to the presence of national referral guidance and the potential of the symptoms to be life threatening. Design Cohort study using individual patient data from the health improvement network database in primary care.

Setting United Kingdom.

Participants 5492 patients with postmenopausal bleeding, 23121 with hip pain, and 101212 with dyspepsia from 326 general practices, 2001-7.

Main outcome measures Multivariable associations between odds of immediate referral for postmenopausal bleeding and age and social deprivation; hazard rates of referral for hip pain or dyspepsia and age, sex, and social deprivation. Analyses for dyspepsia were stratified for people aged less than and more than 55 years because referral guidance differs by age.

Results $61.4 \%$ (3374/5492) of patients with postmenopausal bleeding, $17.4 \%$ (4019/23121) with hip pain, and 13.8\% (13944/101 212) with dyspepsia were referred. The likelihood of referral for postmenopausal bleeding declined with increasing age: the adjusted odds ratio for patients aged 85 or more compared with those aged 55-64 was 0.39 (95\% confidence interval 0.31 to 0.49 ). Patients aged 85 or more with hip pain were also less likely to be referred than those aged 55-64 $(0.68,0.57$ to 0.81$)$. Women were less likely than men to be referred for hip pain (hazard ratio $0.90,95 \%$ confidence interval 0.84 to 0.96 ). More deprived patients with hip pain or dyspepsia (if aged $<55$ ) were less likely to be referred. Adjusted hazard ratios for those in the most deprived Townsend fifth compared with the least deprived were 0.72 (95\% confidence interval 0.62 to 0.82 ) and 0.76 (0.68 to 0.85$)$, respectively. No socioeconomic gradient was evident in referral for postmenopausal bleeding.

Conclusions Inequalities in referral associated with socioeconomic circumstances were more likely to occur in the absence of both explicit guidance and potentially life threatening conditions, whereas inequalities with age were evident for all conditions.

\section{INTRODUCTION}

The United Kingdom's National Health Service is publicly funded. Its central tenet is to provide universal healthcare to all those in need, irrespective of their social characteristics. Despite this, inequalities in healthcare use have been widely described. Although socially disadvantaged, older people ( $>74$ years), and women are more likely to consult their general practitioner, the more socially advantaged, men (for some conditions), and younger people $(<65$ years $)$ are more likely to receive secondary care. ${ }^{1-6}$

These studies base their findings on volumes of attendance or receipt of interventions and so it is unclear whether inequalities occur once patients are within the secondary sector or at the point of entry to specialist care. Within the NHS, general practitioners play a pivotal part in controlling access to specialist care, and so factors explaining variations in referral rates have long been a focus of attention. ${ }^{7}$ However, the aim of these studies has been to understand the extent to which factors related to the patient, general practitioner, and general practitioner's practice explain the wide variations in referral rates (ranging from twofold to 20-fold) that have been reported. Rather than examining the influence of patients' sociodemographic characteristics on referral, these studies have standardised referral rates for such characteristics to examine their effect on the observed variation.

The effectiveness of reforms such as the NHS Cancer Plan and National Service Frameworks in reducing inequalities in health partly depends on the ability of all patients to access high quality specialist care without delay. ${ }^{38}$ Yet these initiatives have concentrated on issues such as the quality of services and decision making within secondary care. Until recently, the need to address pathways to care to tackle issues such as persisting inequalities in survival for common cancers received little recognition.

Meanwhile NHS resources are increasingly devolved to primary care on the basis that patients can receive better quality care if the primary sector manages the care process and the interface with secondary care. ${ }^{9}$ Hence a need exists to understand better the complex factors that influence this interface. To contribute to this research and to understand further 
the point in the care pathway at which inequalities arise, we undertook a national study to examine the extent to which referral for defined symptoms from primary care varied according to patients' age, sex, and socioeconomic circumstances. We hypothesised that sociodemographic variations in referral would be less likely to occur for potentially life threatening conditions and for those symptoms with national guidance on referral and more likely to occur for symptoms where there was clinical uncertainty about the decision to refer.

\section{METHODS}

We examined individual patient data using the health improvement network, a widely used database in primary care. The database comprises over 15 years of individual level medical and therapeutic data on more than six million patients from 358 general practices in the United Kingdom. Practices that use the database are broadly representative of practices in the United Kingdom for patients' characteristics. ${ }^{10}$ The health improvement network includes longitudinal anonymised data for each registered individual on age, sex, medical diagnosis, symptom records, health promotion activity, referrals, and prescriptions. Recording of consultations and prescriptions is comparable to national statistics on consultations and prescriptions. ${ }^{10}$ The database includes an area based indicator of patients' socioeconomic circumstances. Each enumeration district (around 150 households) is assigned a Townsend deprivation score. ${ }^{11}$ These districts are divided into national fifths and patients are assigned a quintile score according to the enumeration district in which they live.

As practices join the health improvement network it takes some time before historical patient records are fully entered into the database and before all patient data are computerised, leading to initially incomplete data. To ensure reliable complete data as far as possible, we applied several quality control measures.

\section{Criteria applied to symptoms}

- Symptoms that consistently result in presentation to general practitioners (rather than, for example, to accident and emergency)

- Symptoms or conditions where referral is a common outcome; symptoms that are specific enough to relate to a particular diagnosis that may require referral-for example, "poor vision" may be secondary to refractive errors, which do not require referral to secondary care, or to cataracts that do require referral (because we were unable to distinguish the underlying cause for poor vision and therefore the appropriateness of referral, we could not include "poor vision" in our list of symptoms for study. Furthermore, referral guidance varies according to the underlying condition. It was therefore necessary to be able to establish the most likely underlying condition from presenting symptom codes to draw conclusions about the necessity of referral for these symptoms)

- The desirability to include both medical and surgical conditions to widen the representativeness of our findings to referral to both physicians and surgeons

- The need to include a "reference" condition-that is, one for which most patients should be referred early to secondary care (to check the quality of the referral data in the health improvement network dataset)
Firstly, we included patients from the time that their practice data records met predefined standards for acceptable computer use - that is, consistently recording at least one medical record, one additional health data record, and at least two prescriptions on average per patient per year. Secondly, we restricted our sample of practices to those that had acceptable mortality rates during the study period - that is, rates consistent with the practice's demographic profile. ${ }^{12}$ Five practices lacked acceptable mortality rates and were excluded from the analysis. Thirdly, to ensure as far as possible that referrals were recorded contemporaneously and reliably, we included practices from the point when their referral rates were consistently within two standard deviations of the mean for that practice. This was to account for information on referral also being subject to a delay in entry to the database, leading to some practices showing considerable variation in referral rates. Recording of referrals was unreliable for 27 practices by the end of the study period so we did not analyse data from these practices. A total of 326 practices were analysed (see web extra for characteristics of included and excluded practices).

\section{Study design}

We identified the most common symptoms associated with referral by examining four routinely available data sources (see web extra). ${ }^{13-15}$ We found close agreement between the datasets. We then applied the a priori set of criteria (box) to the list of symptoms obtained.

On application of these criteria just three symptoms were identified for further study: postmenopausal bleeding, hip pain, and dyspepsia. National guidance states that women with postmenopausal bleeding (who are not receiving hormone replacement therapy) should be referred to secondary care urgently to exclude endometrial cancer. ${ }^{16}$ In contrast, we chose hip pain in patients aged 55 and over, assuming that for most this would be due to osteoarthritis. ${ }^{17}$ Guidelines acknowledge that "there is very little evidence on which to base decisions about who to refer," which suggests that greater variation in decisions about referral may occur. ${ }^{18}$ Finally, guidance on referral for dyspepsia includes an age criterion whereby urgent referral for diagnostic endoscopy is recommended in patients over 55 with unexplained and persistent dyspepsia of recent onset, but not in patients under $55 .{ }^{19}$ We therefore hypothesised that any influence of social factors on referral would differ by age group and that, if present, would be more evident among patients under 55 , for whom the referral criteria were less explicit.

The study period was 1 January 2001 to 1 July 2007 except for dyspepsia, where the analysis period began on 1 January 2003. National guidelines for postmenopausal bleeding were first published in $2000^{16}$ and guidelines for dyspepsia were revised in $2002 .{ }^{19}$ Thus the analysis periods chosen allowed time for guidelines to be adopted in practice.

Medical diagnoses are coded in the health improvement network using the Read code classification 
scheme. We identified patients consulting their general practitioner with Read codes relating to the relevant symptoms. We limited our analyses to patients aged 18 years and above for dyspepsia; and 55 years and above for postmenopausal bleeding (because the modal age for menopause is 51$)^{20}$ and for hip pain.

To ensure as far as possible that only patients with incident symptoms were examined, we excluded patients who presented with the symptom or who had a related investigation or diagnosis recorded before the start of the study period. We excluded patients with postmenopausal bleeding if they had been prescribed hormone replacement therapy in the preceding six months.

The principal outcome was a record of a related referral to specialist secondary care after presentation at the general practice with the symptom. Referrals included direct access for endoscopy for dyspepsia. We did not count as referrals those appointments solely for non-invasive diagnostic imaging. Referral code lists were developed from Read codes and additional health records. We assumed referral to relate to the study symptom if a referral to an appropriate specialty (for example, orthopaedics for hip pain) or for a relevant invasive investigation was recorded within two weeks of the patient attending primary care with the study symptom.

The window of two weeks for referral was chosen to allow a reasonable time for a referral letter to be generated or recorded if a referral code was not used in the initial consultation for the symptom. We limited this period to two weeks because a longer time interval decreased our level of certainty that patients were being referred for the symptom they presented with and not for another condition. To confirm the validity of our choice of a two week window we compared the number of referrals made within 14 and 30 days of consultation. Overall, 89\% of referrals for hip pain, 93\% for dyspepsia, and 98\% for postmenopausal bleeding made within 30 days of consultation were recorded within 14 days.

To examine the potential confounding effect of comorbidity on referral we considered the number of drugs the patient had been prescribed. ${ }^{21}$ All drugs in the health improvement network dataset are assigned British National Formulary codes. We followed previous practice and counted the number of prescriptions from different subsections of the formulary in the six months preceding first presentation with a study symptom and then analysed comorbidity categorically by groups of $0-1,2-4$, or 5 or more subsections of drugs. ${ }^{22}$

Smoking status, alcohol intake, and body mass index were defined by the record closest to the date of first presentation and in the preceding five years. If no record existed for smoking (current, former, or nonsmoker) in that period, we assigned non-smoking status if patients had a record of "never smoked" over the age of $25 .{ }^{23}$ Alcohol intake was categorised as being under or over the recommended limit for sex. ${ }^{24} \mathrm{We}$ considered smoking and high body mass index as having a potential confounding effect on referral for hip pain, and smoking, body mass index, and alcohol intake as having potential confounding effects on referral for dyspepsia. These factors may influence a general practitioner's decision to refer.

\section{Statistical analysis}

Postmenopausal bleeding

As postmenopausal bleeding should be associated with an immediate referral, we modelled the odds of being referred to secondary care by age group and deprivation fifth, using univariable and multivariable logistic regression.

\section{Hip pain and dyspepsia}

We applied the Cox proportional hazard model to investigate univariable and multivariable associations between the hazard rate of referral and social deprivation, sex, and age group. Patient time was calculated from the date of the first presentation to the first of the following: date of referral, date of death, date that patient left the practice, last data collection from the practice, or end of the study period. Because guidelines for dyspepsia differ for those aged over and under 55, we stratified analyses into these two age groups.

\section{All conditions}

In the multivariable model, we adjusted each factor for all the other factors examined and for comorbidity. Many patients did not have a valid recent record for smoking, body mass index, or alcohol intake so we excluded these confounders from the main analyses but carried out secondary analyses to assess the potential impact of these on the results. For dyspepsia we also tested the interaction between age as a binary variable $(<55$ or $>55)$ and social deprivation. To investigate whether any variations in referral by deprivation changed over time we tested for period effects in regression models, by including an interaction between year of first presentation and deprivation.

We used robust standard errors throughout to account for dependency between patients clustered within the same practice. We also undertook secondary analyses to examine the role of variation between practices, because some practices may differ in their overall likelihood to refer. We therefore compared results from multilevel random intercept regression models, with patients nested in practices, with corresponding simple single level models. The degree of attenuation of the odds or rate ratios of referral by age, sex, or social deprivation in the multilevel random intercept models indicated the extent to which inequalities in sociodemography may be explained by differences in the overall levels of referral between practices. We used multilevel random coefficient models to assess the extent to which residual sociodemographic inequalities within practices varied between practices. For hip pain and dyspepsia we compared Poisson multilevel and single level models because multilevel Cox regression is difficult to carry out in standard statistical packages.

We checked the proportional hazards assumption of the Cox regression models using Schoenfeld residuals 
and by graphing the log cumulative hazard over time. For all analyses we used Stata 10 for Windows.

\section{RESULTS}

Included in the analyses were 5492 patients with postmenopausal bleeding, 23121 with hip pain, and 101212 with dyspepsia (figure). Table 1 shows the characteristics of these patients.

\section{Postmenopausal bleeding}

In total, $3374(61.4 \%)$ patients were referred for postmenopausal bleeding. Univariable analyses showed that the likelihood of referral was not associated with deprivation; however, referral declined significantly with increasing age (table 2). Increasing comorbidity was also associated with a lower probability of referral.

In multivariable analyses, no evidence of variation by social deprivation remained. The reduced odds of referral for those aged over 75 persisted.

\section{Hip pain}

In total, $4019(17.4 \%)$ patients with hip pain were referred. The overall rate of referral was 84.7 per

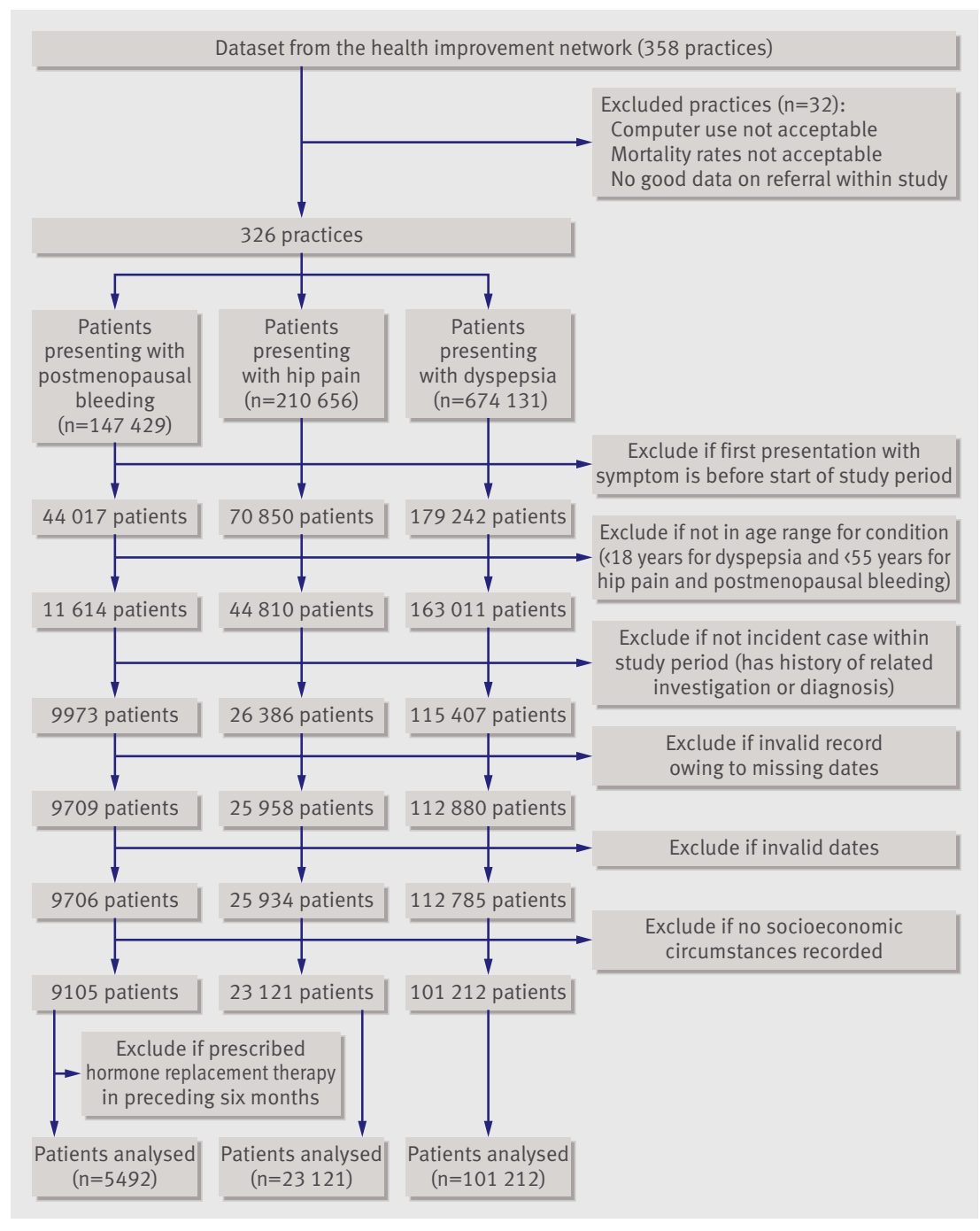

Flow of practices and patients through study
1000 person years at risk (table 3). The univariable analysis showed gradients in likelihood of referral by deprivation fifth, sex, and age group. These findings remained in the multivariable analyses.

Adjusting for smoking status and body mass index in secondary analyses made little difference to the relations of sex, age, and deprivation with referral rate, or to the interactions examined.

\section{Dyspepsia}

Overall, $13944(13.8 \%)$ patients with dyspepsia were referred $(12 \%$ of those aged $<55$ and $17 \%$ of those aged $\geq 55$ ). The overall rate of referral was $80.4 / 1000$ person years at risk (table 4). Univariable analyses revealed a gradient in referral rates by deprivation. When age was analysed as a binary variable, referral rates were higher for those over 55 compared with those under 55 . When age was broken down into 10 year bands compared with the baseline group (55-64 years), however, gradients in referral were observed for older and younger patients $(\mathrm{P}<0.001)$. Referral was least likely in the oldest and youngest patients.

In multivariable analyses those aged 55-64 retained the highest rate of referral, and the decreasing rates for younger and older patients were maintained. The gradient in risk of referral by deprivation was no longer significant and referral rate by sex did not differ significantly. A significant interaction was, however, observed between deprivation and age. For patients under 55, the rate of referral decreased with increasing deprivation but the hazard ratios for those over 55 showed no deprivation gradient in referral. The interaction between age group (under or over 55) and deprivation showed that the difference in deprivation gradient in referral between the two age groups was significant $(\mathrm{P}<0.001)$.

Adjusting for smoking status, alcohol intake, and body mass index in secondary analyses made little difference to the relations of sex, age, and deprivation with referral rate or to the interactions examined. For all conditions, the interaction between deprivation and year of first presentation was non-significant. For all Cox regression analyses, no strong evidence was found of departure from the proportional hazard assumption for any of the models.

For all three symptoms, the effects of age and, for hip pain, sex were unchanged in secondary analyses that adjusted for variations between practices in their overall likelihood of referral (see web extra). Thus the inequalities in relation to age and sex were associated with inequalities within each practice rather than between practices. Random coefficient models showed further significant evidence that practices varied in the degree of inequalities in referral for age and sex. In contrast, the relative reductions in the rate of referral with increasing deprivation category were attenuated by as much as 38\% for hip pain and 26\% for dyspepsia in the random intercept models. Thus the inequalities associated with deprivation for these symptoms could be in part attributed to differences between practices, 
Table 1|Characteristics of patients referred to secondary care

\begin{tabular}{lccc} 
& \multicolumn{3}{c}{ No (\%) of patients referred for symptom } \\
\cline { 2 - 4 } Characteristics & $\begin{array}{c}\text { Dyspepsia } \\
(\mathrm{n}=101212)\end{array}$ & $\begin{array}{c}\text { Hip pain } \\
(\mathrm{n}=23 \text { 121) }\end{array}$ & $\begin{array}{c}\text { Postmenopausal bleeding } \\
(\mathrm{n}=5492)\end{array}$ \\
Men & $48177(44.2)$ & $9061(39.2)$ & $0(0)$ \\
\hline Women & $53035(55.8)$ & $14060(60.8)$ & $5492(100)$ \\
\hline Age group: & & & - \\
\hline$\langle 25$ & $10553(10.4)$ & - & - \\
\hline $25-34$ & $20648(20.4)$ & - & - \\
\hline $35-44$ & $17766(17.6)$ & - & - \\
\hline $45-54$ & $16330(16.1)$ & - & $1309(23.8)$ \\
\hline $55-64$ & $16801(16.6)$ & $8753(37.9)$ & $920(16.8)$ \\
\hline $65-74$ & $10728(10.6)$ & $7501(32.4)$ & $427(7.8)$ \\
\hline $75-84$ & $6629(6.5)$ & $5214(22.6)$ &
\end{tabular}

Deprivation

(Townsend fifth):

\begin{tabular}{|llll}
\hline 1 (least deprived) & $22646(22.4)$ & $6380(27.6)$ & $1499(27.3)$ \\
\hline 2 & $21094(20.8)$ & $5686(24.6)$ & $1383(25.2)$ \\
\hline 3 & $21477(21.2)$ & $4882(21.1)$ & $1110(20.2)$ \\
\hline 4 & $20427(20.2)$ & $3804(16.5)$ & $907(16.5)$ \\
\hline 5 (most deprived) & $15568(15.4)$ & $2369(10.2)$ & $593(10.8)$ \\
\hline
\end{tabular}

Comorbidity

(No of drug types prescribed):

\begin{tabular}{lccc}
\hline $0-1$ & $57364(56.7)$ & $14886(64.4)$ & $3614(65.8)$ \\
\hline $2-4$ & $37933(37.5)$ & $6959(30.1)$ & $1538(28)$ \\
\hline$\geq 5$ & $5915(5.8)$ & $1276(5.5)$ & $340(6.2)$ \\
\hline
\end{tabular}

Smoking status:

\begin{tabular}{lccc}
\hline Non-smoker & $37798(37.3)$ & $8048(34.8)$ & $2461(44.8)$ \\
\hline Current smoker & $25241(24.9)$ & $3277(14.2)$ & $490(8.9)$ \\
\hline Former smoker & $22842(22.6)$ & $6713(29)$ & $1249(22.7)$ \\
\hline Missing data & $15331(15.1)$ & $5083(22)$ & $1292(23.5)$ \\
\hline
\end{tabular}

Alcohol intake:

\begin{tabular}{lccc}
\hline Under limit for sex & $55154(54.5)$ & $11627(50.3)$ & $2790(50.8)$ \\
\hline Over limit for sex & $3972(3.9)$ & $609(2.6)$ & $48(0.9)$ \\
\hline Former drinker & $1778(1.8)$ & $415(1.8)$ & $82(1.5)$ \\
\hline Missing data & $40308(39.8)$ & $10470(45.3)$ & $2572(46.8)$ \\
\hline
\end{tabular}

Body mass index:

\begin{tabular}{lccl}
\hline$\ll 0$ & $50457(49.9)$ & $11213(48.5)$ & $2388(43.5)$ \\
\hline$\geq 30$ & $16378(16.2)$ & $3683(15.9)$ & $1167(21.2)$ \\
\hline Missing data & $34377(34)$ & $8225(35.6)$ & $1937(35.3)$ \\
\hline
\end{tabular}

whereas the effect of patients' deprivation within each practice was relatively small.

\section{DISCUSSION}

In this national study of nearly 130000 patients from 326 practices in primary care, we found associations between patients' sociodemographic characteristics and their likelihood of referral. After adjustment for comorbidity (defined as the number of drug types prescribed), older patients were less likely to be referred for the three conditions examined: postmenopausal bleeding, hip pain, and dyspepsia. This gradient with age was particularly noticeable for postmenopausal bleeding. In addition, women were less likely than men to be referred for hip pain. We also found evidence of decreasing rates of referral with increasing deprivation for patients with hip pain and for those aged under 55 with dyspepsia, but not for patients with postmenopausal bleeding or those over 55 with dyspepsia.

Secondary analysis showed that the effects of age and sex were not explained by variations in overall referral rates between practices but were instead related to younger patients and men with hip pain being more likely to be referred than their older, female counterparts within the same practice. In contrast, inequalities relating to patients' deprivation may in part be explained by general practitioners who work in more deprived areas being in general less likely to refer, rather than more socially disadvantaged patients being less frequently referred than their more affluent counterparts within the same practice.

\section{Comparison with other studies}

Variations in referral rates by age occurred regardless of the criteria for referral or the risk of cancer. These findings of lower referral rates with increasing age have also been shown for patients presenting with symptoms of ovarian cancer and it has been suggested that this may partly explain poor survival rates of older people with cancer in the United Kingdom. ${ }^{25}$ The variations may in part be explained by clinical uncertainty about the likely benefit or harm trade-offs of treatment in older patients or by patient preference. The involvement of patients in decisions about their care fulfils a fundamental tenet of high quality care, but it is important to unravel the origin of patient preferences. Possible explanations for variations in the choices that patients make include systematic differences in expectations for good health and in perceptions of the risk and benefits of defined interventions. ${ }^{26}$ Thus older people may be less willing to undergo procedures because of concerns about good outcomes or adverse consequences. ${ }^{27}$ Concepts of risk may be influenced by beliefs about what are considered "good innings" or "normal" ageing, ${ }^{28}$ and the benefits of treatment for older people. ${ }^{29}$ Such perceptions are likely to be defined, in part, as a result of interactions with doctors. For example, mortality and function after hip surgery are worse for older patients than for younger ones, but the absolute differences are small and on average older people can still expect an improvement in quality of life..$^{30}$ The way in which this information is framed is likely to influence the decision made. With respect to sex inequalities, women may be reluctant to undergo hip surgery because prolonged rehabilitation might jeopardise the responsibility they have to care for others. ${ }^{31}$ Older women are also more likely to live alone and so may be concerned about being dependent on others in the postoperative period. Finally, qualitative research shows that older people tend to minimise their problems ${ }^{32}$ and may therefore be reluctant to seek help from specialists in secondary care.

The lack of information on severity of disease and patient preference meant that it was not possible to ascertain whether differences in referral rates reflected clinically appropriate joint decision making or inequity. The severity of disease is, however, unlikely to explain 
Table 2 |Odds ratios for association between referral to secondary care for postmenopausal bleeding and age, social deprivation, and comorbidity

\begin{tabular}{|c|c|c|c|c|c|c|}
\hline \multirow[b]{2}{*}{ Variables } & \multirow{2}{*}{$\begin{array}{l}\text { No of } \\
\text { patients }\end{array}$} & \multirow{2}{*}{$\begin{array}{l}\text { No (\%) of patients referred } \\
\text { to secondary care }\end{array}$} & \multicolumn{2}{|c|}{ Univariable models } & \multicolumn{2}{|c|}{ Multivariable models* } \\
\hline & & & Odds ratio $(95 \% \mathrm{Cl})$ & $\mathrm{P}$ value $\dagger$ & Odds ratio $(95 \% \mathrm{Cl})$ & $\mathrm{P}$ value $\uparrow$ \\
\hline \multicolumn{7}{|l|}{ Age group: } \\
\hline $55-64$ & 2836 & $1882(66.4)$ & 1 & \multirow{4}{*}{$<0.001$} & 1 & \multirow{4}{*}{$<0.001$} \\
\hline $65-74$ & 1309 & $826(63.1)$ & 0.87 (0.76 to 0.99$)$ & & 0.89 (0.78 to 1.02$)$ & \\
\hline $75-84$ & 920 & $495(53.8)$ & $0.59(0.51$ to 0.69$)$ & & $0.64(0.55$ to 0.74$)$ & \\
\hline$\geq 85$ & 427 & $171(40.1)$ & 0.34 (0.27 to 0.43$)$ & & $0.39(0.31$ to 0.49$)$ & \\
\hline \multicolumn{7}{|c|}{ Deprivation (Townsend fifth): } \\
\hline 1 (least deprived) & 1499 & $936(62.4)$ & 1 & \multirow{5}{*}{0.9} & 1 & \multirow{5}{*}{0.8} \\
\hline 2 & 1383 & $838(60.6)$ & 0.93 (0.79 to 1.08$)$ & & $0.96(0.81$ to 1.14$)$ & \\
\hline 3 & 1110 & $677(61.0)$ & 0.94 (0.77 to 1.15$)$ & & $1.02(0.83$ to 1.26$)$ & \\
\hline 4 & 907 & $558(61.5)$ & 0.96 (0.77 to 1.20$)$ & & 1.05 (0.84 to 1.32$)$ & \\
\hline 5 (most deprived) & 593 & $365(61.6)$ & $0.96(0.77$ to 1.21$)$ & & 1.09 (0.86 to 1.37$)$ & \\
\hline \multicolumn{7}{|c|}{$\begin{array}{l}\text { Comorbidity } \\
\text { (No of drug types prescribed): }\end{array}$} \\
\hline $0-1$ & 3611 & $2351(65.1)$ & 1 & \multirow{3}{*}{$<0.001$} & 1 & \multirow{3}{*}{$<0.001$} \\
\hline $2-4$ & 1539 & $874(56.8)$ & $0.70(0.62$ to 0.80$)$ & & 0.77 (0.68 to 0.87$)$ & \\
\hline$\geq 5$ & 342 & $149(43.6)$ & 0.41 (0.33 to 0.52$)$ & & $0.53(0.42$ to 0.67$)$ & \\
\hline
\end{tabular}

Adjusted for clustering by practice.

*Each risk factor independently adjusted for other risk factors.

$† P$ value for difference in referral hazard between different categories of variable.

our findings because osteoarthritis of the hip is more severe and disabling in lower socioeconomic groups, ${ }^{33}$ postmenopausal bleeding secondary to endometrial cancer increases with age, ${ }^{34}$ and the incidence of stomach cancer increases with age and increasing deprivation. ${ }^{35}$ Therefore our results would be expected to be the converse of those observed (that is, referral would be more likely in more deprived and elderly people) if variations in referral were secondary to unmeasured severity of disease or risk of serious disease.

The conditions studied differed for both the presence of explicit referral criteria and the need to exclude a cancer diagnosis. Both criteria were present for postmenopausal bleeding and dyspepsia in patients aged over 55, and socioeconomic variations in referral rates were not observed. Neither criteria was present for hip pain or dyspepsia under age 55 , and socioeconomic gradients in referral rates were shown. In common with other research ${ }^{36}$ we found that these gradients may in part be explained by a lower likelihood of referral by practices serving socially disadvantaged communities. The reasons for this are, however, unclear. One possibility is that the geographical distribution of specialist services may result in practices in socially disadvantaged areas having poor access to particular specialties. This is unlikely to explain our results because we examined common symptoms requiring access to the services of widely available gynaecologists, orthopaedic surgeons, and gastroenterologists and endoscopists. A second possibility is that practices serving socially disadvantaged communities tend to have higher workloads than those serving more advantaged areas and the patients often have multiple, chronic and complex problems with health and social care. ${ }^{37}$ As a result this may lead general practitioners to exhibit different referral practices. Thirdly, factors such as the type of contract agreed by general practitioners may be associated with both the deprivation of the population they serve and the likelihood of referral.

Finally, factors related to the general practitioner may partly explain our findings. However, no relation has yet been found between referral rates and the individual characteristics of general practitioners, such as age, years of experience, or membership of the Royal College of General Practitioners.

\section{Strengths and limitations of the study}

We used multilevel modelling to assess whether the inequalities identified were associated with variations between or within practices. We were, however, unable to further examine clustering by individual general practitioner within a practice for two reasons. Firstly, because the health improvement network dataset does not include a field for general practitioners who refer. Although anonymised identifiers to distinguish between different people in a practice entering patient data are available, it may be other staff in the practice rather than the referring general practitioner who enter the referrals. Therefore we cannot reliably assign a referral to a particular general practitioner. Secondly, even if we could assign referrals to an individual general practitioner, it would not be possible to identify reliably an "individual general practitioner effect" for chronic conditions, where immediate referral is not indicated (in this case for hip pain and dyspepsia). This is because patients often see a different general practitioner at each visit, making it difficult to assign responsibility for the whole pathway, from initial presentation to referral, to a particular general practitioner.

We used a well established method of assigning socioeconomic circumstances based on the Townsend 
Table $3 \mid$ Hazard ratios for association between referral to secondary care for hip pain and sex, age, social deprivation, and comorbidity

\begin{tabular}{|c|c|c|c|c|c|c|}
\hline \multirow[b]{2}{*}{ Variables } & \multirow{2}{*}{$\begin{array}{c}\text { No of } \\
\text { patients }\end{array}$} & \multirow{2}{*}{$\begin{array}{l}\text { No of patients referred } \\
\text { to secondary care (rate/ } \\
1000 \text { person years at risk) }\end{array}$} & \multicolumn{2}{|c|}{ Univariable models } & \multicolumn{2}{|c|}{ Multivariable models* } \\
\hline & & & Hazard ratio $(95 \% \mathrm{Cl})$ & $\mathrm{P}$ value $\dagger$ & Hazard ratio $(95 \% \mathrm{Cl})$ & P value $†$ \\
\hline Men & 9061 & $1671(94.08)$ & 1 & \multirow{2}{*}{$<0.001$} & 1 & \multirow{2}{*}{0.001} \\
\hline Women & 14060 & $2348(79.15)$ & 0.88 (0.83 to 0.94$)$ & & 0.90 (0.84 to 0.96$)$ & \\
\hline \multicolumn{7}{|l|}{ Age group: } \\
\hline $55-64$ & 8753 & $1477(77.88)$ & 1 & \multirow{4}{*}{$<0.001$} & 1 & \multirow{4}{*}{$<0.001$} \\
\hline $65-74$ & 7501 & $1455(92.10)$ & 1.16 (1.08 to 1.26$)$ & & 1.18 (1.10 to 1.28$)$ & \\
\hline $75-84$ & 5214 & $922(92.25)$ & 1.09 (1.00 to 1.19$)$ & & 1.13 (1.04 to 1.23$)$ & \\
\hline$\geq 85$ & 1653 & $165(61.83)$ & 0.64 (0.54 to 0.76$)$ & & $0.68(0.57$ to 0.81$)$ & \\
\hline \multicolumn{7}{|l|}{$\begin{array}{l}\text { Deprivation } \\
\text { (Townsend fifth): }\end{array}$} \\
\hline 1 (least deprived) & 6380 & $1250(97.79)$ & 1 & \multirow{5}{*}{$<0.001$} & 1 & \multirow{5}{*}{$<0.001$} \\
\hline 2 & 5686 & $1032(88.37)$ & $0.92(0.84$ to 1.01$)$ & & $0.92(0.84$ to 1.01$)$ & \\
\hline 3 & 4882 & $805(79.67)$ & 0.83 (0.75 to 0.91$)$ & & 0.84 (0.75 to 0.92$)$ & \\
\hline 4 & 3804 & $595(76.51)$ & 0.79 (0.71 to 0.89$)$ & & $0.80(0.72$ to 0.90$)$ & \\
\hline 5 (most deprived) & 2369 & $337(66.29)$ & 0.71 (0.61 to 0.81$)$ & & $0.72(0.62$ to 0.82$)$ & \\
\hline \multicolumn{7}{|c|}{$\begin{array}{l}\text { Comorbidity } \\
\text { (No of drug types prescribed): }\end{array}$} \\
\hline 0 to 1 & 14886 & 2811 (83.99) & 1 & \multirow{3}{*}{$<0.001$} & 1 & \multirow{3}{*}{$<0.001$} \\
\hline 2 to 4 & 6959 & $1046(83.42)$ & 0.85 (0.79 to 0.91$)$ & & $0.86(0.80$ to 0.92$)$ & \\
\hline$\geq 5$ & 1276 & 162 (114.09) & $0.83(0.71$ to 0.96$)$ & & $0.87(0.75$ to 1.00$)$ & \\
\hline
\end{tabular}

Adjusted for clustering by practice.

*Each risk factor is independently adjusted for other risk factors.

tP value for difference in referral hazard between different categories of variable unless otherwise specified.

deprivation score for the area of residence. This is an area based indicator of socioeconomic circumstances, which refers to an enumeration district covering a population of about 150 households. This method rests on the assumption that people conform to the socioeconomic profile of their residential area. We would not expect substantial variability in social deprivation in such a small cluster of households. Indeed, it has been shown that Townsend deprivation scores calculated at the enumeration district level are strongly correlated with a similar measure of deprivation calculated at the individual level and are similarly predictive of health. ${ }^{38}$ Nevertheless, with any measure of deprivation some patients will be misclassified. However, this misclassification is likely to be non-differential and, if anything, would attenuate and underestimate any effect of deprivation. In addition, our study included many elderly (and therefore retired) patients for whom individual measures of deprivation are less valid. ${ }^{3940}$ In this situation our use of an area level measure of deprivation was most appropriate.

A disadvantage of using routine data is the non-standardised and incomplete coding of referral, which is likely to have led to some underestimation of the number of referrals. We aimed to avoid underestimation by including practices only from the point when their recording of referrals was consistent over time. Twenty seven practices were excluded as their referral rates became consistent only after the end of our study period. Had these practices had consistent referral data and therefore been included in the analysis, we might have seen overall slightly lower referral rates as the excluded practices serve more deprived communities (see web extra for characteristics of the practice); however, there is no reason why results of the difference in referral according to level of deprivation should be affected.

Our finding that $61 \%$ of women with postmenopausal bleeding were referred to secondary care compares favourably with the $41 \%$ found in a study using another UK primary care database. ${ }^{41}$ In addition, once referral data were being consistently recorded, all practices had referral rates that were within the ranges seen in a review, ${ }^{7}$ which examined referral rates per 1000 consultations from several studies. These findings suggest adequate completeness of recording of referral in the health improvement network.

To ensure that we did not include referrals unrelated to the study symptom, we applied a two week cut-off point for the recording of referrals. This may reduce the number of related referrals observed but there is no reason to believe that recording of referrals or administration of the database would be differentially affected by patients' age, deprivation, or sex.

It is possible that we failed to include some eligible cases where general practitioners coded diagnoses rather than symptoms. To minimise this we included diagnostic codes where possible. Thus for hip pain we included codes for osteoarthritis of the hip, and for dyspepsia we included codes for reflux and oesophagitis. The effect of missing some cases that were coded as diagnoses would be to reduce our sample size. However, this should not affect the results of differences in referral by age, sex, or deprivation. 
Table $4 \mid$ Hazard ratios for association between referral to secondary care for dyspepsia and sex, age, social deprivation, and comorbidity

\begin{tabular}{|c|c|c|c|c|c|c|}
\hline \multirow[b]{2}{*}{ Variables } & \multirow{2}{*}{$\begin{array}{c}\text { No of } \\
\text { patients }\end{array}$} & \multirow{2}{*}{$\begin{array}{l}\text { No of patients referred to secondary } \\
\text { care (rate/1000 person years at risk) }\end{array}$} & \multicolumn{2}{|c|}{ Univariable models } & \multicolumn{2}{|c|}{ Multivariable models* } \\
\hline & & & Hazard ratio $(95 \% \mathrm{Cl})$ & $\mathrm{P}$ value $\dagger$ & Hazard ratio $(95 \% \mathrm{Cl})$ & $\mathrm{P}$ value $†$ \\
\hline Male & 44737 & $6362(82.81)$ & 1 & \multirow{2}{*}{0.002} & 1 & \multirow{2}{*}{0.144} \\
\hline Female & 56475 & $7582(78.46)$ & 0.94 (0.91 to 0.98$)$ & & 0.98 (0.94 to 1.01$)$ & \\
\hline \multicolumn{7}{|l|}{ Age: } \\
\hline$<55$ & 64431 & $7538(66.88)$ & 1 & \multirow{2}{*}{$<0.001$} & 1 & \multirow{2}{*}{$<0.001$} \\
\hline$\geq 55$ & 36781 & $6406(105.43)$ & 1.54 (1.47 to 1.61$)$ & & 1.54 (1.48 to 1.61$)$ & \\
\hline \multicolumn{7}{|l|}{ Age group: } \\
\hline$<25$ & 10553 & $672(37.10)$ & 0.33 (0.30 to 0.36$)$ & \multirow{8}{*}{$<0.001$} & 0.33 (0.30 to 0.37$)$ & \multirow{8}{*}{$<0.001$} \\
\hline $25-34$ & 20648 & 1917 (52.49) & $0.48(0.45$ to 0.51$)$ & & $0.48(0.45$ to 0.51$)$ & \\
\hline $35-44$ & 17766 & $2367(74.84)$ & 0.69 (0.65 to 0.73$)$ & & 0.68 (0.65 to 0.72$)$ & \\
\hline $45-54$ & 16330 & $2761(98.70)$ & 0.89 (0.85 to 0.93$)$ & & 0.88 (0.84 to 0.93$)$ & \\
\hline $55-64$ & 16801 & 3150 (112.85) & 1 & & 1 & \\
\hline $65-74$ & 10728 & $1890(104.40)$ & 0.93 (0.88 to 0.99 ) & & 0.94 (0.89 to 0.99 ) & \\
\hline $75-84$ & 6629 & $1016(94.53)$ & 0.82 (0.76 to 0.89 ) & & 0.84 (0.78 to 0.90$)$ & \\
\hline$\geq 85$ & 1757 & $171(69.45)$ & 0.54 (0.46 to 0.64$)$ & & $0.56(0.47$ to 0.66$)$ & \\
\hline \multicolumn{7}{|l|}{$\begin{array}{l}\text { Deprivation } \\
\text { (Townsend fifth): }\end{array}$} \\
\hline 1 (least deprived) & 22646 & $3513(91.02)$ & 1 & \multirow{5}{*}{$<0.001$} & 1 & \multirow{5}{*}{0.013} \\
\hline 2 & 21094 & 3041 (84.05) & 0.93 (0.87 to 0.98$)$ & & 0.93 (0.88 to 0.99 ) & \\
\hline 3 & 21477 & $2874(77.52)$ & $0.86(0.80$ to 0.91$)$ & & $0.90(0.85$ to 0.96$)$ & \\
\hline 4 & 20427 & 2646 (75.92) & 0.83 (0.76 to 0.91$)$ & & 0.91 (0.83 to 1.00$)$ & \\
\hline 5 (most deprived) & 15568 & $1870(69.88)$ & 0.77 (0.69 to 0.85$)$ & & 0.87 (0.79 to 0.96$)$ & \\
\hline \multicolumn{7}{|c|}{$\begin{array}{l}\text { Comorbidity } \\
\text { (No of drug types prescribed): }\end{array}$} \\
\hline $0-1$ & 57364 & 8568 (82.25) & 1 & \multirow{3}{*}{$<0.001$} & 1 & \multirow{3}{*}{$<0.001$} \\
\hline $2-4$ & 37933 & 4668 (74.93) & 0.85 (0.82 to 0.88$)$ & & 0.85 (0.81 to 0.88$)$ & \\
\hline$\geq 5$ & 5915 & 708 (101.25) & 0.92 (0.84 to 1.00$)$ & & 0.89 (0.82 to 0.97$)$ & \\
\hline \multicolumn{7}{|c|}{ Interactionsł comparing Townsend fifths according to age level§ } \\
\hline \multicolumn{7}{|l|}{ Age $<55$ years: } \\
\hline 1 & - & - & - & - & 1 & \multirow{5}{*}{$<0.001$} \\
\hline 2 & - & - & - & - & 0.97 (0.90 to 1.04$)$ & \\
\hline 3 & - & - & - & - & 0.87 (0.81 to 0.94$)$ & \\
\hline 4 & - & - & - & - & $0.84(0.76$ to 0.92$)$ & \\
\hline 5 & - & - & - & - & 0.76 (0.68 to 0.85$)$ & \\
\hline \multicolumn{7}{|l|}{ Age $\geq 55$ years: } \\
\hline 1 & - & - & - & - & 1 & \multirow{5}{*}{0.04} \\
\hline 2 & - & - & - & - & 0.88 (0.81 to 0.95$)$ & \\
\hline 3 & - & - & - & - & 0.89 (0.81 to 0.96$)$ & \\
\hline 4 & - & - & - & - & 0.92 (0.82 to 1.03$)$ & \\
\hline 5 & - & - & - & - & 0.91 (0.81 to 1.03$)$ & \\
\hline \multicolumn{7}{|c|}{$\begin{array}{l}\text { Adjusted for clustering by practice. } \\
\text { *Each risk factor independently adjusted for other risk factors. } \\
\dagger P \text { value for difference in referral hazard between different categories of variable unless specified otherwise. } \\
\ddagger \text { Adjusted for sex, social deprivation, and comorbidity. } \\
\S P<0.001 \text { for interaction between deprivation and age level. }\end{array}$} \\
\hline
\end{tabular}

As an indicator of comorbidity we used simple counts of prescribed drugs. We acknowledge that these do not fully account for the effects of multiple morbidities, disability, or quality of life, all of which influence decisions about referral. However, the performance of several comorbidity scores (including diagnosis code based scores from the international classification of diseases, ninth revision) to control for confounding in epidemiological studies has been compared. ${ }^{21}$ This analysis found that the number of distinct drugs used was the best predictor of future visits to a doctor and of expenditure and was a good predictor of mortality and admissions to hospital. In contrast, diagnosis based scores were the best predictors of future morbidity and mortality. Our study focused on health service use rather than on patient health outcomes. We therefore decided that the score based on number of prescribed drugs was the most appropriate to use in this context.

We could not fully assess the impact of risk factors (smoking, body mass index, alcohol intake) on referral because of the paucity of data. In addition, general 


\section{WHAT IS ALREADY KNOWN ON THIS TOPIC}

Inequalities in healthcare use exist

Socially disadvantaged people, older people, and women are more likely to consult their general practitioner but less likely to receive secondary care

It is unclear whether inequalities occur once patients are within the secondary sector or at the point of entry to specialist care

\section{WHAT THIS STUDY ADDS}

The likelihood of referral to secondary care was associated with patient's age, sex, and social deprivation

Older patients were less likely to be referred for all symptoms, whereas deprivation was associated with lower referral for hip pain and for those aged under 55 with dyspepsia

Inequalities in referral were more likely to occur in the absence of both explicit guidance and potentially life threatening conditions
We thank Steve lliffe and Steve Morris for their comments on the paper Contributors: RR led the study and is the guarantor for the paper. RR and $\mathrm{DMCB}$ had the idea for the research. DMcB undertook the analysis. All authors participated in the study design, analysis, interpretation of results, drafting of the article, and approval of the final draft. All authors had full access to the data and can take responsibility for the integrity of the data and the accuracy of the data analysis.

Funding: The King's Fund provided support for access to the data. RR is partly funded by a National Institute for Health Research public health career scientist award and by the National Institute for Health Research University College London Hospitals/University College London

Comprehensive Biomedical Research Centre. The opinions stated in this paper are those of the authors as individuals, independent from the funding sources. The funding sources had no role in the study design, analysis, interpretation, writing the report or decision to submit the paper for publication

Competing interests: All authors have completed the Unified Competing Interest form at www.icmje.org/coi_disclosure.pdf (available on request from the corresponding author) and declare (1) Financial support for the submitted work from the King's Fund to access the data; (2) RR is partly funded by a National Institute for Health Research Public Health Career Scientist Award and by the National Institute for Health Research University College London Hospitals/University College London Comprehensive Biomedical Research Centre; (3) No spouses, partners, or children have relationships with commercial entities that might have an interest in the submitted work; and (4) have no non-financial interests that may be relevant to the submitted work.

Ethical approval: This study was approved by the London Research Ethics Committee, National Research Ethics Service (REC reference No 08/ H0718/82).

Data sharing: Statistical code available from the corresponding author at dulciemcbride@googlemail.com.

1 Campbell SM, Roland MO. Why do people consult the doctor? Fam Pract 1996;13:75-83.

2 Raine R. Does gender bias exist in the use of specialist health care? J Health Serv Res Policy 2000;5:237-49.

3 Department of Health. National service framework for older people. DH, 2001.

4 Goddard M, Smith P. Equity of access to health care services: theory and evidence from the UK. Soc Sci Med 2001;53:1149-62.

5 Morris S, Sutton M, Gravelle H. Inequity and inequality in the use of health care in England: an empirical investigation. Centre for Health Economics, University of York, 2003.

6 Dixon A, Le Grand J, Henderson J, Murray R, Poteliakhoff E. Is the British National Health Service equitable? The evidence on socioeconomic differences in utilization. J Health Serv Res Policy 2007;12:104-9.

7 O'Donnell CA. Variation in GP referral rates: what can we learn from the literature? Fam Pract 2000;17:462-71.

8 Department of Health. The NHS cancer plan. DH, 2000.

9 Miller P, Craig N, Scott A, Walker A, Hanlon P. Measuring progress towards a primary care-led NHS. Br J Gen Pract 1999;49:541-5.

10 Raine R, Wong W, Ambler G, Hardoon S, Petersen I, Morris R, et al. Sociodemographic variations in the contribution of drug prevention to stroke survival at middle and older ages: cohort study. BMJ 2009;338:b1279.

11 Townsend P, Phillimore P, Beattie A. Inequalities in health in the northern region. Northern Regional Health Authority and University of Bristol, 1986.

12 Maguire A, Blak BT, Thompson M. The importance of defining periods of complete mortality reporting for research using automated data from primary care. Pharmacoepidemiol Drug Saf 2009;18:76-83.

13 Surender R, Bradlow J, Coulter A, Doll H, Stewart Brown S. Prospective study of trends in referral patterns in fundholding and non-fundholding practices in the Oxford region, 1990-4. BMJ 1995;311:1205-8.

14 Health Episode Statistics. 2008. www.hesonline.nhs.uk/Ease/ servlet/ContentServer?sitelD=1937\& categorylD=894

15 Department of Health. 2008. http://www.dh.gov.uk/en/ Publicationsandstatistics/Statistics/Performancedataandstatistics/ ReferraltoTreatmentstatistics/DH_089411.

16 Department of Health. Referral guidelines for suspected cancer. DH, 2000.

17 D’Ambrosia RD. Epidemiology of osteoarthritis. Orthopedics 2005;28(2 suppl):s201-5.

18 Dieppe P. Fortnightly review: management of hip osteoarthritis. BMJ 1995;311:853-7.

19 British Society of Gastroenterology. Dyspepsia: management guidelines. BSG, 2002 practitioner or service, or interactions between these factors. More research, including in-depth qualitative studies, is required to understand the complex determinants of inequalities in referral from primary care. 
20 Campbell S, Monga A, ed. Gynaecology by ten teachers. 17 ed. Arnold, 2000.

21 Schneeweiss S, Seeger JD, Maclure M, Wang PS, Avorn J, Glynn RJ. Performance of comorbidity scores to control for confounding in epidemiologic studies using claims data. Am J Epidemiol 2001;154:854-64.

22 Walters K, Rait G, Petersen I, Williams R, Nazareth I. Panic disorder and risk of new onset coronary heart disease, acute myocardial infarction, and cardiac mortality: cohort study using the general practice research database. Eur Heart J 2008;29:2981-8.

23 Department of Health. New GMS contract QOF implementation dataset and business rules-smoking indicator set. DH, 2008.

24 Department of Health. 2008. www.dh.gov.uk/en/Publichealth/ Healthimprovement/Alcoholmisuse/DH_085385.

25 Tate A, Nicholson A, Cassell J. Are GPs under-investigating older patients presenting with symptoms of ovarian cancer? Observational study using General Practice Research Database. Br J Cancer 2010;102:947-51.

26 Katz JN. Patient preferences and health disparities. JAMA 2001;286:1506-9.

27 Hawker GA, Wright JG, Coyte PC, Williams II, Harvey B, Glazier R, et al. Differences between men and women in the rate of use of hip and knee arthroplasty. N Engl J Med 2000;342:1016-22.

28 Williams A. Intergenerational equity: an exploration of the 'fair innings' argument. Health Econ 1997;6:117-32.

29 Bowling A. Ageism in cardiology. BMJ 1999;319:1353-5.

30 Santaguida PL, Hawker GA, Hudak PL, Glazier R, Mahomed NN, Kreder $\mathrm{HJ}$, et al. Patient characteristics affecting the prognosis of total hip and knee joint arthroplasty: a systematic review. Can J Surg 2008;51:428-36.

31 Karlsen E, Daltroy L, Liang M, Eaton H, Katz J. Gender differences in patient preferences may underlie differential utilization of elective surgery. Am J Med 1997;102:534.

32 Walters K, Iliffe S, Orrell M. An exploration of help-seeking behaviour in older people with unmet needs. Fam Pract 2001;18:277-82.

33 Hawker GA, Wright JG, Glazier RH, Coyte PC, Harvey B, Williams JI, et al. The effect of education and income on need and willingness to undergo total joint arthroplasty. Arthritis Rheum 2002;46:3331-9.
34 Gredmark T, Kvint S, Havel G, Mattsson L. Histopathological findings in women with postmenopausal bleeding. Br J Obstet Gynaecol 1995;102:133-6.

35 Steward A, Wood H. Stomach. In: ONS. Cancer atlas of UK and Ireland. ONS, 2005.

36 Majeed A, Bindman AB, Forrest C, Weiner JP. Specialist referral rates among primary care physicians in the united kingdom: association with patient characteristics and comparison with referral rates among primary care physicians in the USA. Academy for Health Services Research and Health Policy Meeting. Abstr Acad Health Ser Res Health Policy Meet 2001;18:89.

37 Mercer S, Watt G. The inverse care law: clinical primary care encounters in deprived and affluent areas of Scotland. Ann Fam Med 2007;5:503-10

38 Adams J, Ryan V, White M. How accurate are Townsend deprivation scores as predictors of self-reported health? A comparison with individual level data. J Public Health (Oxf) 2005;27:101-6.

39 Krieger N, Williams DR, Moss NE. Measuring social class in U.S. public health research: concepts, methodologies, and guidelines. Annu Rev Public Health 1997;18:341-78.

40 Grundy E, Holt G. The socioeconomic status of older adults: how should we measure it in studies of health inequalities? J Epidemiol Community Health 2001;55:895-904.

41 Parker C, Hippisley-Cox J, Coupland C, Vinogradova Y. Rectal and postmenopausal bleeding: consultation and referral of patients with and without severe mental health problems. BrJ Gen Pract 2007; 57:371-6.

42 North of England Dyspepsia Guideline Development Group. Dyspepsia: managing dyspepsia in adults in primary care. North of England Dyspepsia Guideline Development Group, 2004.

43 Moller AM, Pedersen T, Vellebro N, Munksgaard A. Effect of smoking on early complications after elective orthopaedic surgery. J Bone Joint Surg Br 2003;85-B:178-81.

44 Coulthard M, Chow YH, Dattani N, White C, Baker A, Johnson B. Health. In: ONS. Focus on social inequalities. ONS, 2004.

Accepted: 14 September 2010 